immunosuppressive treatment allowed such an infection to become disseminated. From the start of her illness the patient was thought to have contracted an infection from one of her cats. She admitted to close contact with them and her previous ringworm was further evidence of this. But the puzzling fact remains that Sooty's antibody profile was suggestive of a subgroup A infection while the patient's antibody response suggested infection with a subgroup B Chlamydia.

Because of the multiple treatment we cannot attribute the patient's recovery to any one drug. Rifampicin, however, is active against $C$ trachomatis infection of the eye $\mathrm{e}^{4}$ and so may have been beneficial.

1 Spencer, E S, Danish Medical Bulletin, 1975, 22, 234.

2 Treharne, J D, Darougar, S, and Jones, B R, Fournal of Clinical Pathology, $1977,30,510$.

${ }^{3}$ Schachter, J, Ostler, H B, and Meyer, K F, Lancet, 1969, 1, 1063.

${ }^{4}$ Darougar, S, et al, British fournal of Ophthalmology, 1977, 61, 255.

5 Treharne, J D, et al, in Nongonococcal Urethritis and Related Infections, ed D Hobson and K K Holmes, p 214. American Society for Microbiology, 1977.

(Accepted 31 August 1978)

Departments of Virology and Nephrology, St Bartholomew's Hospital, London EC1, and Department of Virology, Institute of Ophthalmology, London WC1

P D GRIFFITHS, BSC, MB, research assistant

R I LECHLER, MRCP, senior house officer

J D TREHARNE, PHD, senior lecturer

\section{Antenatal diagnosis of fetal duodenal atresia by ultrasonic scan}

Fetal malformations of the central nervous system can be detected early by ultrasonic examination. Gastrointestinal lesions, however, many of which may require immediate surgical correction after delivery, are more difficult to find.

\section{Case history}

A healthy 26-year-old woman whose first pregnancy had been uncomplicated booked at 14 weeks and attended the antenatal clinic regularly. The uterine size was consistently two weeks too large for her dates. Ultrasound scan at 19 weeks and six days verified the given dates. All other findings were normal. At 30 weeks there was apparent polyhydramnios: the uterus was tense and four weeks too large for dates. $X$-ray examination at 33 weeks showed no fetal abnormality. At 34 weeks the patient was admitted in early premature labour. Intravenous ritodrine was given to decrease uterine activity and betamethasone to reduce the possibility of neonatal respiratory distress.

A further ultrasonic scan four days after admission showed a biparietal measurement of $93.0 \mathrm{~mm}$-again consistent with the patient's dates. The fetal head and spine were normal. On taking cross-sections of the upper fetal abdomen, however, double fluid-filled structures were clearly visible (see figure). Measurement of the total internal uterine volume $\left(6942 \mathrm{~cm}^{3}\right)$ confirmed the apparent polyhydramnios. ${ }^{1}$ Slight uterine activity persisted over the next two weeks. It increased at 36 weeks. The cervix was found to be 5 -cm dilated. Labour was allowed to proceed, amniotomy was performed, and six hours later a $2150 \mathrm{~g}$ female infant was delivered normally. A nasogastric tube was passed immediately and a large amount of bile-stained fluid aspirated. A clinical diagnosis of Down's syndrome was subsequently confirmed by chromosomal analysis. Erect $x$-ray examination of the infant at 12 hours showed the "double-bubble" shadow in her abdomen, confirming duodenal atresia. The parents refused surgical treatment. The baby died at 8 days. Permission for necropsy was not given.

\section{Comment}

Polyhydramnios, in the absence of a maternal cause, may be associated with fetal abnormality in as many as half the cases. Lloyd and Clatworthy $^{2}$ found $43 \%$ abnormal fetuses in their series of 76 pregnancies complicated by polyhydramnios. High small-bowel obstruction, proximal to the ligament of Treitz, was associated with polyhydramnios in $47 \%$ of 49 pregnancies. Obstruction distal to the ligament of Treitz did not appear to give rise to excess liquor. Fonkalsrud et $a l^{3}$ in a review of 503 infants with congenital duodenal atresia or stenosis found additional congenital malformations in $48 \%$. Polyhydramnios was present in $45 \%$ of these cases and prematurity or dysmaturity (defined as a birth weight below $2500 \mathrm{~g}$ ) in $51 \%$. Down's syndrome was present in $30 \%$.

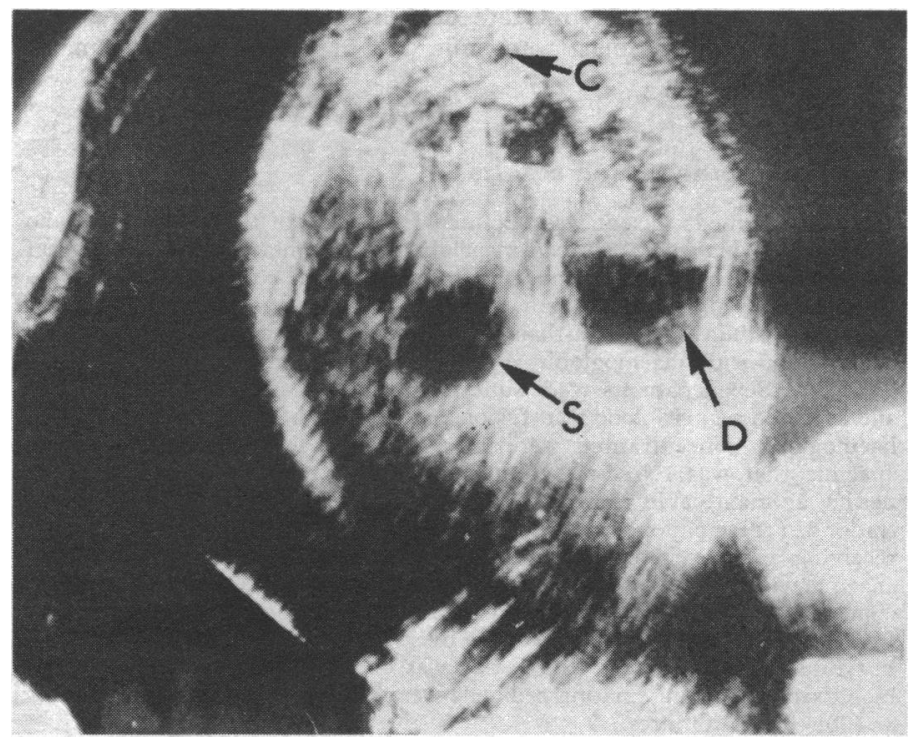

Cross-section of upper fetal abdomen scanned by unfocused transducer at frequency of $5 \mathrm{MHz}$. Note double cystic structures corresponding to stomach (S), dilated proximal duodenum (D), and fetal spinal canal (C).

Our case illustrates the importance of ultrasonic examination of the fetal abdomen in cases of polyhydramnios when cephalic and spinal abnormalities have already been excluded. In two previously reported cases 45 there was duodenal atresia without Down's syndrome. Down's syndrome was not foreseen in our case. Amniocentesis for chromosomal analysis might be considered once duodenal atresia is diagnosed.

1 Gohari, P, Berkowitz, R L, and Hobbins, J, American fournal of Obstetrics and Gynecology, 1977, 127, 255.

2 Lloyd, J R, and Clatworthy, H W, Pediatrics, 1958, 21, 903.

${ }^{3}$ Fonkalsrud, E W, de Lorimer, A A, and Hayes, D M, Pediatrics, 1969, 43, 79 .

${ }^{4}$ Loveday, B J, Barr, B A, and Aitken, J, British fournal of Radiology, 1975 , 48, 1031 .

${ }^{5}$ Duenhoelter, J H, Santos Ramos, R, and Rosenfield, C R, Obstetrics and Gynecology, 1976, 47, 618.

(Accepted 1 August 1978)

Department of Obstetrics and Gynaecology, University of Liverpool $H$ GEE, MB, research fellow

U ABDULLA, MB, MRCOG, senior lecturer

\section{Serum 2-hydroxybutyrate dehydrogenase activity and ineffective erythropoiesis}

High levels of plasma lactate dehydrogenase activity are commonly found in patients with megaloblastic anaemia. ${ }^{1}$ Imperfect erythroblast maturation in this disorder results in the destruction of vast numbers of developing red cells rich in the anionic lactate dehydrogenase $(\mathrm{LDH})$ isoenzymes $\mathrm{LDH}_{1}$ and $\mathrm{LDH}_{2}$. This is believed to be the cause of the 
increased plasma enzyme levels ${ }^{2}$ and it has become common practice to regard plasma $\mathrm{LDH}_{1}$ and $\mathrm{LDH}_{2}$ values as an index of ineffective erythropoiesis in other haematological disorders.

Recently developed techniques allow the amount of ineffective iron turnover in the marrow to be measured. Turnover is greatly increased in those conditions, particularly megaloblastic anaemia and homozygous $\beta$-thalassaemia, where ineffective erythropoiesis is a prominent feature, and its measurement gives a quantitative assessment of the destruction of erythroblast cytoplasm. We compared ineffective iron turnover with the serum activity of $\mathrm{LDH}_{1}$ and $\mathrm{LDH}_{2}$ measured specifically as 2-hydroxybutyrate dehydrogenase (HBD) activity in patients with megaloblastic anaemia and in several other haematological disorders.

\section{Patients, methods, and results}

Fully informed consent was obtained from each of the 29 patients who took part in this study. Six had megaloblastic anaemia as a result of either folate or vitamin $B_{12}$ deficiency; their haemoglobin concentrations ranged from 5.5 to $8.3 \mathrm{~g} / \mathrm{dl}$ and they had a mean cell volume of 121-139 $\mathrm{fl}$. Five patients had heterozygous $\beta$-thalassaemia with a haemoglobin concentration of $10.5-13.5 \mathrm{~g} / \mathrm{dl}$; haemoglobin $\mathrm{A}_{2}$ was $3.9-7.4 \%$ and haemoglobin $\mathrm{F}$ was $0 \cdot 9-2 \cdot 4 \%$. Seven patients were suffering from homozygous $\beta$-thalassaemia and required regular blood transfusions; at the time of the investigation their haemoglobin concentrations were $9 \cdot 1$ and $13.2 \mathrm{~g} / \mathrm{dl}$. Five patients had an anaemia that was refractory to haematinic treatment and resulted from neither an identifiable genetic defect nor malignancy. Haemoglobin concentrations in these patients ranged from 6.6 to $12.6 \mathrm{~g} / \mathrm{dl}$ and four of them were receiving regular blood transfusions. Six patients had iron deficiency anaemia with haemoglobin concentrations of $7 \cdot 1-9 \cdot 9 \mathrm{~g} / \mathrm{dl}$ and a serum ferritin concentration of less than $10 \mu \mathrm{g} / \mathrm{l}$. Ineffective iron turnover was derived from the plasma ${ }^{59} \mathrm{Fe}$ clearance curve over 14 days. ${ }^{3}$ Serum for 2 -hydroxybutyrate dehydrogenase (HBD) assay was obtained from a clotted venous blood sample. Contaminating red cells were removed by centrifuging twice at $300 \mathrm{~g}$ for 15 minutes.

In the patients with megaloblastic anaemia both the HBD levels and the ineffective iron turnover were greater than normal (see figure), and there was a clear relationship between ineffective iron turnover and HBD. By contrast, the HBD levels remained essentially normal in other patients in whom ineffective iron turnover was also considerably increased. One of the patients with iron deficiency anaemia had a serum HBD concentration greater than 500 IU/1 yet both he and the other anaemic patients had ineffective iron turnover within the normal range.

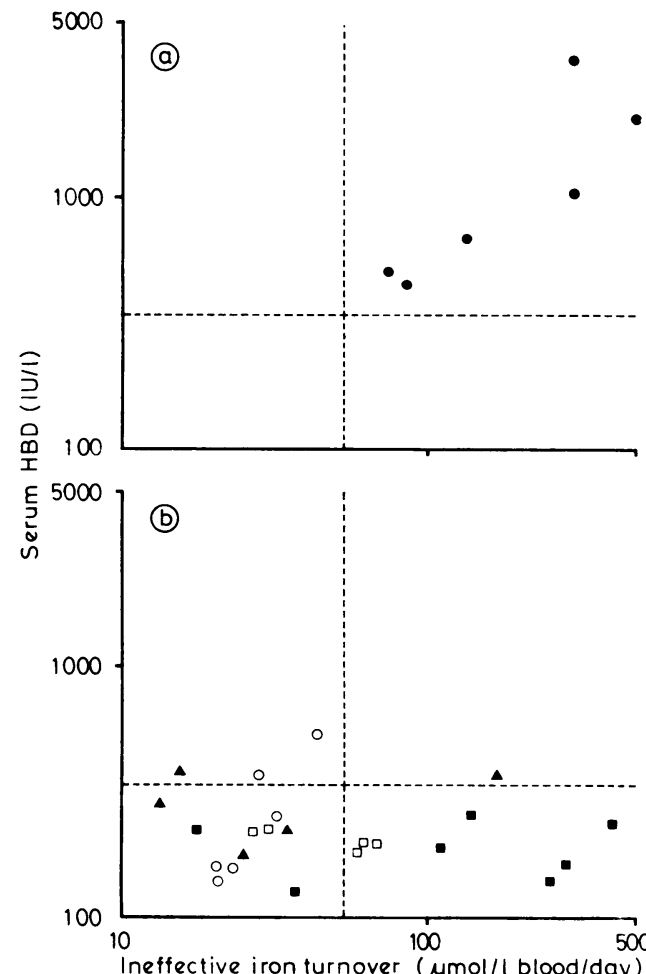

Serum HBD and ineffective iron turnover in $(a)$ patients with megaloblastic anaemia $(O)(\mathrm{r}=0.84 ; t=3 \cdot 14$; $\mathrm{P}<0.05) ;(b)$ patients with iron deficiency anaemia $(0)$ refractory anaemia $(\boldsymbol{\Delta})$, heterozygous $\beta$-thalassaemia $(\square)$, or homozygous $\beta$-thalassaemia $(\square)$

Dotted lines show normal upper limit for each value: SHBD-350 IU/1; ineffective iron turnover$54 \mu \mathrm{mol} / \mathrm{l} \mathrm{blood} / \mathrm{day}$

\section{Comment}

This study shows that the increased serum HBD activity in patients with megaloblastic anaemia is related to ineffective erythropoietic iron turnover and supports the suggestion ${ }^{4}$ that the serum enzyme is derived from the destruction of megaloblast cytoplasm. In other conditions where ineffective erythropoiesis is known to be increased the serum HBD level was not increased even though ineffective iron turnover in these patients was up to 20 times the normal level and was similar to that found in the megaloblastic patients. Both we and others ${ }^{5}$ have, however, found increased serum HBD concentrations (up to $2300 \mathrm{IU} / \mathrm{l}$ ) in patients with intravascular, but not intramedullary, haemolysis. Our results show that serum HBD activity cannot be used as an index of ineffective erythropoiesis in disorders other than megaloblastic anaemia.

${ }^{1}$ Zimmerman, M J, West, M, and Heller, P, Archives of Internal Medicine, $1958,102,115$

${ }^{2}$ Libnoch, J A, Yakulis, V J, and Heller, P, American fournal of Clinical Pathology, 1966, 45, 302

${ }^{3}$ Cavill, I, et al, Scandinavian fournal of Haematology, 1976, 17, 160.

${ }^{4}$ Emerson, P M, Withycome, W A, and Wilkinson, J H, British fournal of Haematology, 1967, 13, 656.

5 Wanderman, K L, et al, American Heart fournal, 1975, 90, 405.

(Accepted 15 September 1978)

Departments of Haematology and Medical Biochemistry, Welsh National School of Medicine, University Hospital of Wales, Cardiff CF4 4XW

I CAVILL, PHD, MRCPATH, principal scientific officer

C RICKETTS, PHD, scientific officer

G J GRIFFITHS, $\mathrm{MB}, \mathrm{BCH}$, registrar (now senior registrar in chemical pathology, Bolton Royal Infirmary, Bolton BL1 4QS)

G H ELDER, MD, MRCPATH, professor of medical biochemistry

D TREVETT, FIMLS, chief medical laboratory scientific officer

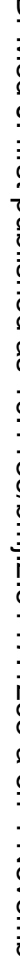

Chlormethiazole edisylate, 5-(2-chloroethyl)-4-methylthiazole ethanedisulphonate, is chemically related to the thiazole nucleus of the thiamine (vitamin $B_{1}$ ) molecule. It is a central nervous system depressant, probably acts on the cortex, and has an early sedative, hypnotic effect. It is widely used to counter the alcohol withdrawal syndrome, including delirium tremens, and to treat psychomotor agitation, anxiety-tension states, sleep disturbances, and also status epilepticus. A wide variety of structurally unrelated drugs including tranquillisers are known to interfere with serum concentrations of prolactin. ${ }^{12}$ We report the effect of chlormethiazole on serum prolactin levels in 16 male alcoholics.

\section{Patients, methods, and results}

Sixteen male chronic alcoholics in hospital (mean age $43.4 \pm 2.6$ SEM) with normal serum prolactin concentrations were included in the study. Three (patients 4,11 , and 16) were found on liver biopsy to have steatosis. None of the patients showed clinical or biochemical evidence suggestive of cirrhosis. All totally abstained from alcohol during the period of the study. All blood samples were collected at the same time of the day and under identical conditions. Serum prolactin concentrations were measured by radioimmunoassay at the time of admission and again after treatment (seventh day). No patient suffered from a malabsorption syndrome or any other condition known to interfere with serum prolactin concentrations, and there was nothing to suggest that absorption of drugs by mouth was impaired. The data were analysed by Student's $t$ test.

All patients were given our routine detoxification treatment for alcoholism. This includes the following drugs: (1) chlormethiazole edisylate (Heminevrin capsules $500 \mathrm{mg}, 192 \mathrm{mg}$ base per capsule), three capsules thrice daily for three days, two capsules twice daily for two days, and one capsule thrice daily for one day-a total, on average, of 42 capsules (8.064 $\mathrm{g}$ of chlormethiazole base) over six consecutive days; (2) intravenous Parentrovite (high potency) $10 \mathrm{ml}$ daily for five days.

The mean $( \pm$ SEM $)$ serum prolactin concentration on admission was

.

